\title{
GOVERNO DILMA NA MÍDIA IMPRESSA: ESTUDO SOBRE OS AGENTES EM DESTAQUE NOS TEXTOS DAS MANCHETES 123
}

\author{
Valmir Teixeira de Araújo ${ }^{4}$
}

\begin{abstract}
RESUMO
A partir de uma compreensão do conceito do jornalismo impresso brasileiro foi elaborado um estudo sobre a cobertura política do Governo Dilma, nas manchetes publicadas nos três maiores jornais impressos do país - Folha de S. Paulo, O Globo e O Estado de S. Paulo. A pesquisa foi realizada a partir da cobertura midiática do primeiro ano da gestão - 2011 - por se tratar de um período chave para se refletir sobre a relação estabelecida entre a imprensa brasileira e o Governo Dilma. No estudo foi utilizada uma metodologia de Análise de Conteúdo, que possibilitou identificar a proporção da cobertura midiática dos referidos jornais sobre o Governo Dilma e também verificar quais foram os agentes destacados nos textos das manchetes, isto é, quais os personagens foram citados nestas chamadas. Os resultados possibilitaram considerar um destaque para o Governo Dilma nos três veículos analisados, com pouca diferenciação e também a utilização prioritária do nome da presidente e de outros agentes, como ministros, para se referir ao governo nos textos das manchetes
\end{abstract}

Palavras-chave: Mídia; impresso; Dilma; manchetes.

\begin{abstract}
From an understanding of the concept of Brazilian printed journalism, a study on the political coverage of the Dilma Government was elaborated in the headlines published in the three largest printed newspapers in the country - Folha de S. Paulo, O Globo and O Estado de S. Paulo. The research came from the media coverage of the first year of management - 2011 - as it is a key period to reflect on the relationship established between the Brazilian press and the Dilma Government. In the study, a Content Analysis methodology was used, which enabled the identification of the proportion of media coverage of the aforementioned newspapers on the Dilma Government and also to verify which agents were prominent in the headline texts, that is, which characters were cited in these titles. The results made it possible to consider a prominence for the Dilma government in the three vehicles analyzed, with little differentiation and also the priority use of the name of the president and other agents, as ministers, to refer to the government in the headlines texts.
\end{abstract}

Keywords: Media; newspaper; Dilma; headlines.

\section{RESUMEN}

A partir de una comprensión del concepto del periodismo impreso brasileño se elaboró un estudio sobre la cobertura política del Gobierno Dilma, en los titulares publicados en los tres mayores periódicos impresos del país - Folha de S. Paulo, O Globo y El Estado de São Paulo. La encuesta fue realizada a partir de la cobertura mediática del primer año de la gestión - 2011 - por tratarse de un período clave para reflexionar sobre la relación establecida entre la prensa brasileña y el Gobierno Dilma. En el estudio se utilizó una metodología de Análisis de Contenido, que posibilitó identificar la proporción de la cobertura mediática de dichos periódicos sobre el Gobierno Dilma y también verificar cuáles fueron los agentes destacados en los textos de los titulares, es decir, cuáles los personajes fueron citados en estas llamadas. Los resultados posibilitaron considerar un destaque para el Gobierno Dilma en los tres vehículos analizados, con poca diferenciación y también la utilización prioritaria del nombre de la presidenta y de otros agentes, como ministros, para referirse al gobierno en los textos de los titulares.

Palabras clave: Medios; impreso; Dilma; titulares.

\section{INTRODUÇÃO}

Em uma sociedade democrática, com participação popular no processo de escolha de seus representantes, a visibilidade midiática apresenta-se como fundamental para a construção

\footnotetext{
${ }^{1}$ Trabalho apresentado no XXXIX Congresso Brasileiro de Ciências da Comunicação da Sociedade Brasileira de Estudos Interdisciplinares da Comunicação (Intercom).

${ }^{2}$ Enviado: $13 / 02 / 2017$

Aceito: $25 / 05 / 2017$

${ }^{3}$ DOI: $10.5380 /$ recp.v8i1.50659

${ }^{4}$ Doutorando do Programa de Pós-Graduação em Comunicação Social da Universidade Metodista de São Paulo, email: valmir.ptu@gmail.com.
} 
ou desconstrução da imagem de um agente político. Faz-se necessário destacar que nos sistemas democráticos da atualidade, os meios de comunicação possuem destaque, sobretudo no cotidiano da política partidária, ao reproduzir discursos, fomentar debates, suscitar questões que chegam a impactar a agenda da esfera política.

Importa destacar que os veículos de comunicação, ao selecionarem ou destacarem alguns assuntos ligados à imagem de determinado agente político, ignoram ou minimizam o destaque a outros temas e acabam por causar impactos nas esferas políticas. Logo, torna-se importante a realização de estudos voltados para a análise dos conteúdos midiáticos, sobre os assuntos ligados aos agentes políticos.

Nessa discussão que envolve imprensa e política, torna-se relevante discorrer sobre o papel do jornal imprenso, numa realidade em que a instantaneidade ganhou força com a internet e o surgimento do jornalismo nas plataformas digitais. Compreende-se como importante no presente artigo discorrer, especificamente, sobre a relação dos grandes jornais impressos brasileiros e a política partidária. Para tanto, realizou-se uma pesquisa empírica a partir de publicações de jornais impressos, com o auxílio metodológico da Análise do Conteúdo.

O presente trabalho tem como objetivo discorrer sobre os agentes destacados nos textos das manchetes dos jornais impressos publicados no ano de 2011, relacionados ao governo da então presidente Dilma Rousseff, que se reelegeu em 2014, mas deixou o cargo após um processo de impeachment, em 2016. O primeiro ano da gestão foi selecionado, em razão de se tratar de um período não eleitoral e oferecer subsídios importantes para uma reflexão sobre a relação que se estabeleceu entre o Governo Dilma e a imprensa brasileira - de modo específico os grandes jornais impressos.

Para seleção dos veículos, elegeu-se como critério analisar os maiores veículos da mídia impressa. Foram considerados como os maiores jornais impressos brasileiros a Folha de S. Paulo (Folha), O Globo (Globo) e O Estado de S. Paulo (Estadão), que tiveram respectivamente as maiores médias diárias de circulação de exemplares no ano de 2011, conforme aponta a Associação Brasileira de Jornais (ANJ).

O artigo é estruturado em quatro partes, sendo que a primeira é constituída a partir de uma reflexão de caráter bibliográfico a respeito de mídia e política, a partir da visão de alguns autores que norteiam a posição teórica apresentada. Em seguida, discorre-se sobre os veículos de comunicação analisados. Depois, discute-se a metodologia utilizada na pesquisa, a Análise de Conteúdo. E por fim, são apresentadas as informações da pesquisa empírica sobre os agentes destacados nas manchetes e realizada uma discussão, buscando um resgate aos argumentos teóricos propostos na primeira parte do trabalho. 
ARAUJO, V. T. Governo Dilma na mídia impressa: estudo sobre os agentes em destaque nos textos das manchetes

\section{MÍDIA E POLÍTICA}

A partir do pressuposto de que os meios de comunicação são formas simbólicas do poder torna-se fundamental discutir a relação existente entre a veículos de comunicação e as esferas políticas. Nesse sentido, evidencia-se a importância de se discutir o papel dos meios de comunicação num ambiente democrático, como o da realidade brasileira.

A discussão que envolve a relação entre mídia e política passa, necessariamente, pelo jornalismo político - parte ou editoria jornalística que aborda, especificamente, os fatos e as questões relacionadas, diretamente com o âmbito da política, num conceito que envolve as questões relacionadas às disputas dos agentes pelo poder. Destacam-se a visibilidade e a importância da mídia no privilegiado espaço do jogo de poder e das relações políticas, onde a construção de imagens com legitimidade em meio à sociedade pode ser compreendida como uma questão essencial. Assim, os diversos atores envolvidos no jogo pelo poder, com imagem associada aos partidos políticos, sindicados, entidades patronais e órgãos da sociedade civil, procuram legitimidade por meio dos meios de comunicação, o que destaca seu papel desses veículos nas disputas da esfera política.

Pesquisadores como Motta (2002), Thompson (1998) e Miguel (2002) discorrem sobre o papel da mídia no cotidiano da política partidária. A partir de uma análise sobre essas leituras, é possível argumentar que os meios de comunicação se apresentam como um instrumento importante na relação entre os agentes políticos e a sociedade. Nessa perspectiva, torna-se aceitável considerar que, em sociedades democráticas, a imprensa necessita do jogo de poder e o jogo de poder necessita da imprensa.

O Poder Executivo, por exemplo, tende a buscar os meios de comunicação, para garantir uma boa imagem midiática e ganhar legitimação diante da opinião pública, garantindo assim melhores condições de governabilidade e elegibilidades futuras. Os jornais, por sua vez, necessitam de fontes, para divulgar informações sobre os poderes e os agentes da esfera política, para manterem sua legitimação, enquanto fonte de informação da opinião pública.

Nesse ‘jogo’ entre os campos da mídia e da política, se faz necessário compreender a existência de uma relação próxima e ao mesmo tempo distante, uma vez que o agente político busca os meios de comunicação em razão de sua visibilidade - elemento indispensável para a permanência no poder de uma figura que depende do apoio popular. Por outro lado, a mídia necessita de fontes, para produzir 'furos' jornalísticos, pautas exclusivas e conteúdos diferenciados. Para Miguel e Biroli (2010, p.3), a colaboração entre jornalistas e fontes tem 
uma faceta menos explícita: “Os atores políticos antecipam o que é capaz de atrair os jornalistas, enquanto estes últimos antecipam as reações das suas fontes às histórias noticiadas".

Nesse sentido, Miguel e Biroli (2010, p.37) destacam que a imprensa não apenas contribui para refletir uma realidade do campo da formação política representativa, mas também desempenha uma "função ativa", na reprodução, pois "não só descrevem uma situação de fato (o monopólio da atividade política pelos profissionais), mas a naturalizam diante de seu público e contribuem para sua perpetuação".

É necessário pensar que a mídia, assim como o sistema político partidário, está sensível a alterações:

\begin{abstract}
O nosso sistema de mídia não é estático e apresenta mudanças e transformações que devem ser notadas pelo impacto potencial na relação com o sistema político e na dinâmica democrática, especialmente num contexto de um sistema de mídia com baixa diversidade externa e sem um jornalismo político e/ou partidário expressivo no plano nacional que ofereça ao leitor perspectivas políticas competitivas. (AZEVEDO, 2006, p. 22)
\end{abstract}

Ainda conforme Azevedo (2006, p. 109) ao final da ditadura militar e a partir da redemocratização brasileira foi possível "especular" que a cobertura política midiática brasileira tenderia para a "diversidade", em razão da consolidação do jornalismo comercial e da competição entre os veículos. Contudo, afirma que não há elementos que confirmem esta especulação, a partir da estruturação dos veículos de comunicação brasileiros.

Para melhor discutir a relação dos meios de comunicação e a política, importa discorrer sobre as funções do jornalismo, que em conformidade com Thompson (1998, p. 209), são: prezar pela vigilância do poder público, fomentar o debate pluralista e contribuir para a mobilização social. Nesse sentido, o jornalismo também pode ser visualizado como um instrumento com potencial de fomentar a discussão para resolução de conflitos, além de protagonizar um destaque de mediação, principalmente nas relações políticas.

Contudo, Bourdieu (1997) relativiza o poder do campo do jornalismo, em razão de sua "dependência":

\begin{abstract}
O campo do jornalismo tem uma particularidade: é muito mais dependente das forças externas que todos os outros campos de produção cultural, campo da matemática, campo da literatura, campo jurídico, campo científico. Ele depende muito diretamente da demanda, está sujeito à sanção do mercado, do plebiscito, talvez mais ainda que o campo político. A alternativa do "puro" ou do "comercial" que se observa em todos os campos ai se impõe com uma brutalidade particular e peso do polo comercial (BOURDIEU, 1997, p. 76)
\end{abstract}

Por fim, torna-se interessante fazer uma reflexão sobre o que é a produção jornalística e/ou dos meios de comunicação. Para Champagne (1997, p.64), é imprescindível discutir os 
ARAUJO, V. T. Governo Dilma na mídia impressa: estudo sobre os agentes em destaque nos textos das manchetes

conteúdos midiáticos, tendo em vista as interpretações dos jornalistas ou dos veículos de comunicação, como "representações", que em muitos casos encontram-se "afastadas da realidade". Para o autor, por muitas vezes a maneira como os meios de comunicação atuam reforça as interpretações espontâneas e mobiliza, portanto, os prejulgamentos e tende, por isso, a redobrá-los".

Em suma, é possível destacar que a relação entre os meios de comunicação e a política pode ser caracterizada como intensa, conflituosa e importante para ser acompanhada, analisada e discutida.

\section{GRANDES VEÍCULOS}

Seguindo uma tendência da maior parte dos países ocidentais, os meios de comunicação no Brasil passaram por um processo de fortalecimento, na segunda metade do século XX, que permitiu o crescimento de alguns veículos, que por sua vez conquistaram destaque e legitimidade, em nível nacional. Contudo, as estruturas dos meios de comunicação no país tornaram-se cada vez mais monopolizadas, o que implica diretamente no seu papel em meio à sociedade.

Em conformidade com Sodré (1988), os grandes jornais impressos como O Estado de S. Paulo, O Globo e a Folha de S. Paulo ganharam ainda mais notoriedade no cenário nacional, além da emissora de televisão Rede Globo, que passou por um período de forte expansão, sobretudo, no período militar, possibilitando que seus telejornais alcançassem grandes públicos na realidade brasileira. Apesar dos telejornais alcançarem um número maior de pessoas, os jornais impressos conquistaram legitimidade para alguns temas, como política e economia.

As razões que possibilitaram a monopolização dos veículos de comunicação no Brasil, em parte, foram consequência de uma movimentação da política global. Nas últimas décadas do século XX, o mundo assistiu a um processo de enfraquecimento da política ideológica, focada na distinção de partidos entre direita e esquerda, sobretudo com o fim dos regimes socialistas e da Guerra Fria, que por sua vez levou ao fortalecimento da imprensa comercial e apartidária, norteadas pelo mercado e a guerra de audiência (AZEVEDO, 2004, p. 46).

De acordo com Habermas, o fato de os veículos de comunicação serem geridos como um empreendimento possibilitou o surgimento de grandes estruturas sujeitas às pressões comerciais. O jornal acaba por evoluir para um empreendimento capitalista, caindo no campo dos interesses estranhos à empresa jornalística e que procuram influenciá-la. A história dos 
grandes jornais, na segunda metade do século XIX, demonstra que a própria imprensa se tornou sensível às necessidades do mercado publicitário.

Como proposto por Bourdieu (1997, p 104), ao discorrer sobre os veículos de comunicação, de forma geral, torna-se importante ponderar a existência dos mais sensíveis às seduções dos poderes econômicos e políticos e, por outro lado, àqueles mais aplicados em defender os princípios e os valores da profissão. Contudo, ao se pensar nas grandes estruturas de comunicação, como os jornais de abrangência nacional, torna-se importante não inferir generalizações, em relação aos valores da profissão jornalística.

Algumas especificidades do jornalismo brasileiro colaboram para uma maior dependência de outros campos (como o político e o econômico) e, consequentemente, com uma menor aplicação dos valores profissionais. A imprensa se desenvolveu tardiamente no Brasil, no início do século XIX, vivenciando pouca a fase do jornalismo crítico e, em partes, independente do poder econômico. Além disso, o monopólio familiar esteve muito presente no desenvolvimento dos principais jornais impressos do Brasil, impondo barreiras ao crescimento e fortalecimento de jornais alternativos e, por consequência, surgiu uma grande imprensa orientada, prioritariamente para elites e permeável à influência dos políticos, (AZEVEDO, 2006, p. 89).

Ainda cabe destacar que na primeira parte do século $\mathrm{XX}$, quando alguns jornais brasileiros como O Estado de S. Paulo, o Jornal do Brasil, O Globo e a Folha de S. Paulo desenvolveram suas estruturas para circular em nível nacional, a maior parte da população brasileira era analfabeta. Logo, apenas após a popularização dos meios eletrônicos (Rádio e TV), que no Brasil só ocorreu na segunda metade do século XX, a maioria da população passou a ser informada sobre os acontecimentos, através do jornalismo. Por consequência, os meios eletrônicos, sobretudo a TV, passaram a atrair uma proporção maior do mercado publicitário de anúncios, o que possibilitou a ampliação dessas estruturas.

Com o intuito de barrar o processo de monopolização dos meios de comunicação no Brasil, a Constituição de 1946 passou a limitar a participação dos estrangeiros nas empresas de comunicação, proibindo que essas empresas fossem controladas por pessoas de outros países, sociedades anônimas ou pessoas jurídicas, a fim de permitir a plena identificação dos proprietários da mídia e restringir o capital estrangeiro nesse setor, conforme aponta Azevedo (2006, p. 99). Segundo este autor, a medida impediu o controle dos meios de comunicação por grupos estrangeiros, mas não barrou a formação de verdadeiros conglomerados de comunicação, que reúnem diferentes canais de imprensa, majoritariamente controlados por algumas famílias. 
ARAUJO, V. T. Governo Dilma na mídia impressa: estudo sobre os agentes em destaque nos textos das manchetes

No caso brasileiro, os anúncios publicitários garantiram o desenvolvimento desse monopólio, formado por poucos veículos de comunicação que expandiram suas estruturas, investiram pesado em seu layout (no caso de jornais impressos e revistas) e em equipamentos de alta tecnologia (sobretudo para os meios eletrônicos como os telejornais) e passaram a dominar o mercado de publicações jornalísticas. Após essa consolidação, surge um círculo vicioso, pois estes grandes veículos concentraram quase a totalidade dos recursos destinados à publicidade e, consequentemente, obtiveram maiores condições de investir em inovações, tecnologias e demais ações que possibilitassem maior visibilidade, o que implicou na sua legitimação perante a sociedade.

Os conglomerados de comunicação no Brasil são formados por um grupo pequeno de empresas e, no caso do jornalismo impresso, é possível citar três grandes veículos que há décadas constituem-se como os principais jornais impressos do país, tendo em vista o número de tiragens diárias desses periódicos: Folha de S. Paulo, O Globo e O Estado de S. Paulo. Esses são jornais de tradição, reconhecidos na sociedade e de alcance nacional, possuindo agências de notícias utilizadas como fontes por outros jornais regionais de todo o país.

Em 2011, a média de circulação da Folha de S. Paulo foi de 286.398 unidades diárias, contra 263.046 do O Globo e de 256.259 do O Estado de S. Paulo - correspondendo respectivamente ao primeiro, segundo e terceiro lugar no ranking dos jornais de modelo standard no Brasil, segundo a Associação Nacional de Jornais (ANJ). Importa ainda destacar, a existência de outros grandes jornais impressos do Brasil, mas com tiragens inferiores aos citados e com uma forte abrangência regional como os periódicos gaúchos Zero Hora e o Diário Gaúcho, o Estado de Minas, de Belo Horizonte (MG) e o Correio Brasiliense, do Distrito Federal.

Por outro lado, Folha de S. Paulo, O Globo e O Estadão apresentam-se como referência nos estudos sobre a grande mídia impressa brasileira. Destacam-se algumas características comuns aos três grandes jornais impressos do Brasil como o número de tiragens e a instalação de suas sedes ou sucursais nos mais importantes centros urbanos do país e de correspondentes em outras grandes cidades, além de serem controlados por famílias tradicionais como a Marinho (O Globo), a Mesquita (Estadão) e a Frias (Folha de S. Paulo).

\section{PROCEDIMENTOS METODOLÓGICOS}

O estudo em questão se propôs a realizar uma pesquisa empírica, por meio de uma perspectiva metodológica da Análise de Conteúdo, a partir das manchetes principais dos 
maiores jornais impressos brasileiros, em número de tiragem, conforme dados da Associação Nacional dos Jornais: Folha de S. Paulo (Folha), O Globo e O Estado de S. Paulo (Estadão). O estudo considerou os conteúdos publicados em 2011 - primeiro ano do Governo Dilma. Para tanto, foi realizada um levantamento de dados em que foram coletadas e analisadas todas as capas dos três jornais, de $1^{\circ}$ de janeiro e 31 de dezembro de 2011. O foco do estudo foram os agentes, isto é, personagens destacados nos textos das manchetes, relacionadas ao Governo Dilma.

O primeiro ano da gestão foi escolhido por se tratar de um período não-eleitoral, em que é possível fazer uma análise da cobertura midiática, sem levar em consideração a existência de um pleito, que por sua vez justificaria a exposição dos candidatos. Além disso, acredita-se que a análise desse período contribui com uma reflexão sobre a relação estabelecida entre a imprensa brasileira e o governo da presidente Dilma, que viria a deixar o cargo em 2016 após um processo de impeachment.

As técnicas da Análise de Conteúdo, utilizadas para realização da pesquisa são habituais nas pesquisas do campo da Comunicação. Conforme Bardin (2011, p. 42), está é uma técnica investigativa, a partir de uma descrição sistemática e quantitativa do conteúdo da comunicação, que visa interpretações e compreensões do material estudado. Por meio deste estudo, torna-se possível analisar procedimentos sistemáticos e objetivos da descrição imersos nos conteúdos das mensagens a serem explorados, a partir de uma pesquisa científica.

Neste sentido, é possível descrever a Análise de Conteúdo como uma metodologia de pesquisa voltada para a descrição e interpretação de conteúdos como documentos e textos, incluindo material jornalístico. A utilização desta metodologia permite descrições sistemáticas e qualitativas que são fundamentais na interpretação de mensagens, com o intuito de compreender o significado do material analisado.

Bardin (2009) sustenta que o primeiro contato que o pesquisador tem com os documentos da análise constitui-se na "leitura flutuante", que por sua vez possibilita o surgimento das hipóteses, objetivos e questões norteadoras da pesquisa. A partir da leitura flutuante podem ser definidos os procedimentos metodológicos e suas respectivas aplicações, visando à organização do material - dados - e consequentemente a realização da pesquisa científica.

A partir dos dados extraídos neste trabalho foi possível mensurar o quantitativo de publicações em que os respectivos jornais destacaram o Governo Dilma e quais os agentes presentes nos textos das manchetes, isto é, personagens presentes nas manchetes do caderno de política. Importa destacar que para elaborar o presente trabalho, atentou-se apenas às manchetes 
ARAUJO, V. T. Governo Dilma na mídia impressa: estudo sobre os agentes em destaque nos textos das manchetes

sobre o Governo Dilma, com um recorte nas chamadas relacionadas a então presidente da República, aos atos e ações do Palácio do Planalto e dos ministros diretamente ligados à Dilma, ou seja, apenas o primeiro escalão do governo.

Os agentes destacados nos textos das manchetes foram definidos a partir da necessidade de se realizar uma análise a respeito dos personagens presentes nos textos - as manchetes. Por meio desse exame foi possível mensurar o quantitativo de agentes presentes na pesquisa, a constância dos mesmos em cada jornal analisado e o compartilhamento ou o não desses nomes, entre os três veículos.

Preliminarmente, a análise sobre os agentes destacados nas manchetes buscou quantificar a menção do nome da presidente Dilma, nas publicações relacionadas ao seu Governo. Além disso, essa etapa permitiu também destacar quais outros agentes foram recorrentes nas manchetes sobre o Governo Dilma.

Para realização da pesquisa foi preciso trabalhar com a categorização dos dados levantados e nesse sentido dividir a realização da Análise de Conteúdo por etapas. A primeira é a pré-análise, fase voltada à organização, na qual são preparadas as primeiras informações do estudo, o que inclui a escolha dos materiais a serem analisados. É aqui que se comprova a possibilidade de realização da pesquisa, a partir de um prévio tratamento dos resultados obtidos e as primeiras interpretações.

O segundo momento é o da codificação do material, quando os dados brutos são transformados em unidades de amostras ou unidades de registro. Por sua vez, a unidade de registro da pesquisa é quando se delimita o elemento unitário, que será submetido à classificação ou categorização da pesquisa. Neste processo, foi necessário identificar a unidade de análise e estabelecer os códigos adicionais, para transformar dados brutos em unidades, possibilitando a decodificação e codificação dos dados.

O procedimento seguinte foi a categorização dos materiais, quando são classificados os elementos a partir de reagrupamentos e de categorias. Em seguida, vem a inferência, quando se inicia a interpretação dos conteúdos, por meio da identificação de grupos por variáveis e as categorizações das seções, efetuando compreensões mais aprofundadas da pesquisa a partir do material coletado.

Para a realização da pesquisa em questão foi necessário constituir o corpus do trabalho, que é o conjunto dos documentos a serem analisados. Segundo Bardin (2011), esses, por sua vez foram submetidos a procedimentos analíticos, a partir do referencial teórico, buscando-se primeiramente a desconstrução dos dados, para posteriormente realizar a análise interpretativa das informações. 
A utilização das técnicas da Análise de Conteúdo foi fundamental para a realização do presente estudo, uma vez que possibilitou a sistematização das etapas da pesquisa como a definição do corpus, a codificação, decodificação, categorização, a inferência, ou seja, a efetivação do percurso metodológico.

\section{ANÁLISE DOS DADOS}

A partir da compreensão defendida na parte teórica desde trabalho, sobre a importância da relação entre os meios de comunicação e a esfera política, apresenta-se nesta sessão informações sobre a pesquisa empírica realizada a partir dos textos das manchetes dos três principais jornais impressos brasileiros - Folha de S. Paulo, O Globo e O Estado de S. Paulo (Estadão) - no ano de 2011. Importante destacar que a discussão gerada nos permite discorrer sobre um possível padrão dos grandes jornais brasileiros, uma vez que focou neste tipo de veículos de comunicação.

A partir dos dados extraídos na pesquisa foi possível identificar um forte destaque dos assuntos relacionados ao Governo Dilma Rousseff, nas manchetes publicadas pelos três jornais analisados ao longo do ano de 2011. Este ponto nos permite fazer uma ligação com a ideia defendida no início deste trabalho e sustentada por Motta (2002), Thompson (1998) e Miguel (2002), de que há uma forte relação entre o que é destacado pelos meios de comunicação e o cotidiano da esfera política.

Quadro 1 - Manchetes do Governo Dilma

\begin{tabular}{|l|l|l|}
\hline \multirow{2}{*}{ Jornais } & \multicolumn{2}{|c|}{ Manchetes Governo Dilma } \\
\cline { 2 - 3 } & Número & Percentual do ano de edições \\
\hline O Globo & 131 & $35,9 \%$ \\
\hline Estadão & 115 & $31,5 \%$ \\
\hline Total & 106 & $29 \%$ \\
\hline
\end{tabular}

Fonte: Autor.

Com base nos dados apresentados no Quadro 1, é possível observar a predominância de assuntos relacionados ao Governo Dilma nas manchetes em destaque, dos principais jornais impressos brasileiros, em 2011 - 32,1\% (352 de 1.0095 manchetes publicadas pelos três jornais). Numa análise restrita à Folha, é possível observar que este foi o jornal que mais 
ARAUJO, V. T. Governo Dilma na mídia impressa: estudo sobre os agentes em destaque nos textos das manchetes

divulgou manchetes principais relacionadas ao Governo Dilma: um total de 131 manchetes, o que corresponde a $36 \%$ do total de suas publicações ao longo de um ano. Já a cobertura midiática do jornal $\mathrm{O}$ Globo foi um pouco menor, mas ainda assim o Governo Dilma foi recorrente com 31,5\% (115 manchetes). O jornal O Estado de S. Paulo (Estadão), dentre os três veículos analisados, foi o que apresentou o menor número de publicações relacionadas ao Governo, com 106 manchetes, o que representa 29\% de destaques nas capas naquele ano.

Uma importante observação que é possível fazer, a partir dos dados apresentados, é a pouca diferenciação dos grandes jornais impressos brasileiros, em relação ao destaque do Governo Dilma. Houve uma pequena variação o que permite reforçar o contraponto apresentado por Azevedo (2006), de que apesar do fortalecimento dos jornais com a redemocratização brasileira, a diversificação de conteúdos midiáticos não estaria garantida.

Ao analisar os textos das manchetes é possível observar que o agente Dilma foi destacado nas manchetes sobre seu governo, em 133 manchetes, o que representa $36 \%$ do total analisado. Contudo, outros agentes também foram destacados nos textos das manchetes.

Quadro 2 - Agentes de Texto

\begin{tabular}{|l|c|c|c|c|c|}
\hline $\begin{array}{c}\text { Agentes do } \\
\text { Texto }\end{array}$ & Descrição & $\begin{array}{c}\text { Estadão - } \\
106 \\
\text { manchetes }\end{array}$ & $\begin{array}{c}\text { 0 Globo - } \\
115 \\
\text { manchetes }\end{array}$ & $\begin{array}{c}\text { Folha - } \\
131 \\
\text { manchetes }\end{array}$ & $\begin{array}{c}\text { Total - 352 } \\
\text { manchetes }\end{array}$ \\
\hline Dilma & $\begin{array}{c}\text { Dilma Rousseff - } \\
\text { Presidente da República }\end{array}$ & $58(55 \%)$ & $40(35 \%)$ & $35(27 \%)$ & $133(35 \%)$ \\
\hline Palocci & $\begin{array}{c}\text { Antônio Palocci - ministro } \\
\text { do Governo Dilma }\end{array}$ & $1(0.9 \%)$ & $11(10 \%)$ & $30(23 \%)$ & $42(12 \%)$ \\
\hline Lula & $\begin{array}{c}\text { Luiz Inácio Lula da Silva - } \\
\text { ex-presidente e aliado de } \\
\text { Dilma }\end{array}$ & $4(4 \%)$ & $9(8 \%)$ & $6(5 \%)$ & $19(5 \%)$ \\
\hline Lupi & $\begin{array}{c}\text { Carlos Lupi, ministro do } \\
\text { Governo Dilma }\end{array}$ & $6(6 \%)$ & $5(4 \%)$ & $4(3 \%)$ & $15(4 \%)$ \\
\hline Mantega & $\begin{array}{c}\text { Guido Mantega - ministro } \\
\text { do Governo Dilma }\end{array}$ & $4(4 \%)$ & $2(1 \%)$ & 0 & $6(2 \%)$ \\
\hline Sarney & $\begin{array}{c}\text { José Sarney - senador } \\
\text { aliado de Dilma }\end{array}$ & $1(0.9 \%)$ & 0 & $1(0.7 \%)$ & $2(0.5 \%)$ \\
\hline Obama & $\begin{array}{c}\text { Barack Obama - } \\
\text { presidente dos Estados } \\
\text { Unidos }\end{array}$ & $2(2 \%)$ & $1(0.8 \%)$ & 0 & $3(0.8 \%)$ \\
\hline Ideli & $\begin{array}{c}\text { Ideli Salvati - ministra do } \\
\text { Governo Dilma }\end{array}$ & $2(2 \%)$ & 0 & 0 & $2(0.5 \%)$ \\
\hline Orlando & $\begin{array}{c}\text { Orlando Silva - ministro } \\
\text { do Governo Dilma }\end{array}$ & $3(3 \%)$ & 0 & 0 & $3(0.8 \%)$ \\
\hline Dirceu & $\begin{array}{c}\text { José Dirceu - ex-ministro } \\
\text { do Governo Lula }\end{array}$ & 0 & $1(0.8 \%)$ & 0 & $1(0.3 \%)$ \\
\hline Aldo & $\begin{array}{c}\text { Aldo Rabelo - ministro do } \\
\text { Governo Dilma }\end{array}$ & 0 & $1(0.8 \%)$ & 0 & $1(0.3 \%)$ \\
\hline FHC & $\begin{array}{c}\text { Fernando Henrique } \\
\text { Cardoso - ex-presidente e }\end{array}$ & 0 & 0 & $2(1 \%)$ & $2(0.5 \%)$ \\
\hline
\end{tabular}




\begin{tabular}{|l|c|c|c|c|c|}
\hline Temer & $\begin{array}{c}\text { opositor ao Governo } \\
\text { Dilma }\end{array}$ & & & & \\
\hline Rossi & $\begin{array}{c}\text { Michel Temer - vice- } \\
\text { presidente da República }\end{array}$ & 0 & 0 & $1(0.7 \%)$ & $1(0.3 \%)$ \\
\hline Alckmin & $\begin{array}{c}\text { Wagner Rossi - ministro } \\
\text { do Governo Dilma }\end{array}$ & 0 & 0 & $1(0.7 \%)$ & $1(0.3 \%)$ \\
\hline $\begin{array}{c}\text { Geraldo Alckmin - } \\
\text { governador de São Paulo } \\
\text { e opositor ao Governo } \\
\text { Dilma }\end{array}$ & 0 & 0 & $1(0.7 \%)$ & $1(0.3 \%)$ \\
\hline
\end{tabular}

Fonte: Autor.

De acordo com o Quadro 2 é possível destacar a proporção de jornais, que ao longo do período da pesquisa, mencionaram o agente de texto Dilma nas manchetes: No Estadão foram 55\% (58 manchetes), no Globo 35\% (40 manchetes) e na Folha 27\% (35 manchetes). Assim, o Estadão foi o jornal que mais citou o nome da presidente nas chamadas do jornal, como na edição do dia 4 de janeiro de 2011: "Dilma suspende distribuição de cargos por crise com PMDB".

Ainda em conformidade com o Quadro 2, chama atenção a presença marcante de outros agentes destacados em manchetes sobre o Governo Dilma, como o então ministro da Casa Civil Antônio Palocci, teve expressiva recorrência nas manchetes - 12\% (46 manchetes). A aparição desse agente foi bastante distinta numa comparação entre os jornais, com um índice bem maior na Folha, com 23\% (30 manchetes), um pouco menor no O Globo, com 10\% (11 manchetes) e de menos de $1 \%$ (apenas uma manchete) no O Estadão. Essa disparidade aponta que a Folha foi o jornal que mais teve publicações sobre o ex-ministro, que no mesmo ano foi apontado em denúncias que levaram a sua saída do cargo no Governo Dilma.

Palocci foi o primeiro ministro a deixar o Governo Dilma, após ter seu nome citado em denúncias de corrupção. "Palocci multiplica seu patrimônio por 20 em 4 [anos]" foi a manchete da Folha do dia 15 de maio de 2011. Essa foi a primeira de uma série de manchetes em jornais brasileiros ‘denunciando' um possível escândalo de corrupção no Governo Dilma. Após ser figura central em mais de 40 manchetes, Palocci deixa a Casa Civil no dia 7 de junho do mesmo ano.

Outros cinco ministros também deixaram o Governo Dilma envolvidos em escândalos: Alfredo Nascimento, do Ministério dos Transportes; Wagner Rossi, da Agricultura; Pedro Novais, do Turismo; Orlando Silva, do Esporte; e Carlos Lupi, do Trabalho. Contudo, apenas Lupi e Rossi tiveram seus nomes destacados nas manchetes dos jornais, sendo que Lupi apareceu 16 vezes e Rossi 1. Estes fatos envolvendo os ministros que saíram no primeiro ano do governo e a repercussão na imprensa, destacando escândalos de corrupção do Governo Dilma, podem contribuir para 
ARAUJO, V. T. Governo Dilma na mídia impressa: estudo sobre os agentes em destaque nos textos das manchetes

reflexões sobre os meios de comunicação e o percurso de Dilma Rousseff como presidente do Brasil.

Outro personagem ou agente presente nos textos das manchetes sobre o Governo Dilma foi o ex-presidente Luiz Inácio Lula da Silva, que conforme o Quadro 2 aparece 19 vezes, sendo 9 no O Globo, 6 na Folha e 5 no Estado. "Dilma demitiu Palocci na hora certa, diz Lula", Folha de S. Paulo, 9 de junho de 2011. Por serem aliados e colegas de partido (ambos do PT), os jornais buscaram relacionar Lula a gestão de Dilma, como mostra o exemplo acima. Além desses, também apareceram personagens como Mantega, Sarney, Obama, Ideli, Dirceu, FHC, Temer e Alckmin.

É interessante refletir que nem todas as menções a nomes são negativas, como na manchete de O Globo do dia 17 de fevereiro de 2011: "Dilma vence $1^{\text {a }}$ batalha na votação do mínimo”. Contudo, compreende-se que o negativo ou positivo para o governo pode ser a soma de uma ação da presidente ou de algum membro do governo, com as "representações" midiáticas dos veículos de comunicação, como bem destaca Champagne (1997, p.64) ao discorrer sobre as coberturas midiáticas.

Em suma, vale resgatar a discussão teórica sobre o papel da mídia, no sentido de refletir sobre a realidade, como destacou Miguel e Biroli (2010, p.37). Nesse sentido, apesar de retratar "fatos", percebe-se que os jornais impressos analisados puderam destacar ou ocultar atores e num recorte específico sobre o Governo Dilma. Assim, é possível observar que outros atores, como os ministros, e o ex-presidente Lula foram também destacados para discorrer sobre o Governo Dilma e desta forma acabaram sendo alocados na representação deste governo na mídia impressa brasileira.

\section{CONSIDERAÇÕES FINAIS}

É possível considerar que as coberturas políticas dos veículos impressos de comunicação, de abrangência nacional, possuem uma forte relação com o cotidiano político/administrativo dos agentes da esfera política. Por esta razão, buscou-se através desta pesquisa apontar o espaço que os principais jornais impressos brasileiros - Folha de S. Paulo (Folha), O Globo e O Estado de S. Paulo (O Estadão) - reservaram para discorrer sobre o Governo Dilma, em um ano que não foi eleitoral como 2011. Primeiramente, foi possível observar que houve um destaque considerável para o Governo Dilma na mídia impressa, uma vez que cerca de um terço das manchetes dos jornais, ao decorrer de um ano, tratava sobre este governo. 
Foi possível também destacar que o quantitativo de manchetes sobre o Governo Dilma entre os três jornais analisados variou pouco, apontando para uma realidade de diversificação tímida de temas de publicação dos três principais jornais impressos analisados, ao menos no ano da pesquisa. Contudo, houve certa diferenciação no que se refere à utilização dos agentes de texto destacados. O número de manchetes sobre o Governo Dilma, que destacou o nome da presidente foi bem menor na Folha e muito maior no Estadão. Por outro lado, na Folha foram utilizados mais outros agentes, principalmente o nome do então ministro Alexandre Palocci, para se referir ao Governo Dilma.

É possível concluir que a mídia impressa brasileira, através dos textos de suas manchetes, destacou o Governo Dilma de forma acentuada e semelhante, porque o número de publicações de um jornal para outro foi relativamente pequeno. É importante destacar ainda que a forte presença do agente "Dilma" como agente de texto nas manchetes pode levar a uma compreensão de personificação das ações do governo com a presidente, principalmente na cobertura do Estadão. Por outro lado, importa destacar que as manchetes também de outros como os ministros envolvidos em escândalos foram muito presentes nos três jornais analisados.

A partir da pesquisa empírica também foi possível refletir sobre a ação dos meios de comunicação ao publicar determinado assunto ou ainda destacar determinado agente no texto da manchete. Neste caso específico, foi possível observar que os jornais analisados buscaram outros agentes, como os ministros envolvidos em escândalos de corrupção ao tratar sobre o governo Dilma. Essa observação pode contribuir com uma reflexão cabível sobre a relação da imprensa brasileiro e o Governo Dilma, uma vez a partir desse estudo é possível observar que os jornais publicaram um número considerável de manchetes no primeiro ano da gestão da presidente Dilma Rousseff.

\section{REFERÊNCIAS BIBLIOGRÁFICAS}

AZEVEDO, F. A. Agendamento Político. In: RUBENS, A. A. C. Comunicação e política: conceitos e abordagens. Edufba, Salvador. 2004.

AZEVEDO, F. A. Mídia e democracia no Brasil: relações entre o sistema de mídia e o sistema político. Opinião Publica v. 12, n. 1, 2006.

BARDIN, L. Análise de Conteúdo. Lisboa: Edições 70. 2011. (Obra original publicada em 1977)

BIROLI, F.; MIGUEL, L. F.; MOTA, F. F. Mídia, eleições e pesquisa de opinião no Brasil (1989-2010): um mapeamento da presença das pesquisas na cobertura eleitoral. Revista Compolítica, v.1, n.1, 2011. 
ARAUJO, V. T. Governo Dilma na mídia impressa: estudo sobre os agentes em destaque nos textos das manchetes

BOURDIEU, P. Sobre a Televisão. Zahar. Editores. 1997.

BRITTOS, V. C. As organizações Globo e a reordenação das comunicações. Revista Brasileira de Ciências da Comunicação, São Paulo, vol. XXIII, n.1, jan./jun. 2000b, p. 57-76.

BUCCI, E. Sobre ética e imprensa. São Paulo: Editora Abril. 2000.

CHAMPAGNE, P. A visão Mediática. In: BOURDIEU P. (org.). A miséria do mundo. Petrópolis, RJ: Vozes, 1997.

CHAIA, V. T. Democracia e escândalos políticos. CHAIA, M. (org). Mídia e política. São Paulo Perspec. v. 15, n. 4, 2001.

HABERMAS, J. Direito e Democracia: entre facticidade e validade. Tradução de Flávio Beno Siebeneichler. Rio de Janeiro: Tempo Brasileiro, 2003.

IBGE. Histórico do Índice Nacional de Preços ao Consumidor Amplo. Disponível em: http://www.portalbrasil.net/ipca.htm. Acesso em 05 de abr. 2014.

MARCONDES, F. C. Comunicação e Jornalismo. A Saga dos Cães Perdidos. São Paulo. Hacker Editores, 2000.

MARTINS, F. Jornalismo Político. São Paulo: Editora Contexto. 2005.

MATOS, C. Jornalismo e política democrática no Brasil. Publifolha. São Paulo. 2008.

MIGUEL, L. F. Os Meios de Comunicação e a prática política. Lua Nova, n. 55-56, 2002.

MIGUEL R. A. A Construção da Notícia. Petrópolis: Ed. Vozes, 2009.

MOTTA. L. G. Imprensa e Poder. Imprensa Oficial - São Paulo. 2002

O GLOBO. Manual de Redação do Jornal O Globo. Rio de Janeiro. 2011.

O ESTADO DE SÃO PAULO. Manual de Redação e Estilo: O Estado de São Paulo. São Paulo. 1997.

ORTIZ, R. A moderna tradição brasileira. Editora Brasiliense. São Paulo. 2009.

SODRÉ, N. História da imprensa no Brasil. Editora Contexto, São Paulo. 1998.

THOMPSON, J. A Mídia e a Modernidade. Editora Vozes. 1998

TRAQUINA, N. Teorias do Jornalismo, Vol.1. Florianópolis: Editora Insular, 2004. 